\title{
Study on Status and Influencing Factors of Rural Left behind Women's Physical Exercise
}

\author{
Yan Chaobing \\ Institute of Physical Education of Jiujiang University, JiangXi Province, China \\ Yan8085@126.com
}

\begin{abstract}
Using the method of literature, questionnaire investigation of present situation of sports women left behind in rural Jiujiang; results show: staying women working time is long, sports consciousness, sports participation rate and the consumption is low, the sports organizations and sports facilities is not high; influencing factors of women left in rural areas in Jiujiang in sports cultural degree, work time and family income.
\end{abstract}

Index Terms - The women left in rural areas; Physical exercise; Present situation; Influencing factors

\section{Introduction}

Participation in sports is a way of life, women's sports behavior is a mirror Chinese women's life changes, but also an approach to enhance the social status of women, the aim of this study is to take part of the administrative village of Jiujiang rural women as the object of study, sports research of them, and combing the factors influencing its participation in sports exercise.

\section{The object of study and method}

\section{A. The object of study}

In 14 Jiujiang rural villages (Zong Shu village, Sun De village, Wang Zhaofan village, Li Tiejiang village, Nong Kezhan Tai Shanju village, Xia Wangchuan village, Xi Xinqiao village, Hai Shanju village, Cui Jialing village, Dong Guan village, $\mathrm{Hu}$ Jia village, Tie Luzeng village, Shang Fangchengjia village) now live woman as an object of investigation, the present situation of sports as the research object.

\section{B. Research methods}

\section{1) Literature}

Through access to China journal net database, collect and left behind women and sports related literature.

2) Questionnaire survey method

Based on literature analysis and expert consultation, design a "Jiujiang rural remaining women's physical exercise status questionnaire", was sent to a relevant expert repeatedly modified, to ensure the validity of the questionnaire. A random survey to village into people's homes in 14 villages of Jiujiang women left behind, and one by one interpretation, and strive to achieve real and effective questionnaire data, every village a total of 30 questionnaires, 420 questionnaires were recovered, take on the spot, 356 valid questionnaires, the effective rate was $84.8 \%$.

3) Mathematical statistics method

The questionnaire data were statistically treated.

\section{The results of study and analysis}

\section{A. Concept definition}

Left behind women, also known as the left behind wife, the husband go out alone or with other family members living in the household of women. With the reform and opening up and the city to speed up the process, the liquidity Chinese continued population increase. The transfer of rural labor force to the city in, because the main migration is male, the elderly, women and children in the household and appeared in the countryside left behind women. With the influx of rural migrant workers in the city, a special group is forming -- they endured many years with her husband separated two lonely, guarding the home of a mu 3 distribute land, support for the elderly, care for children, a shoulder a heavy burden of the family, they were called "left behind women".

\section{B. The basic situation of women left behind}

The survey results as shown in Table I and Table II, left behind women over the age of 45 , the total number of survey $63.1 \%$, and women under 35 years accounted for only $11.5 \%$. In the survey found, left behind women love education level is generally low, primary school and below accounted for $50.2 \%$, while only $3.1 \%$ of women with college degree or above. According to the results of the survey, rural women to work, and the labor intensity is big, the time is more concentrated.

TABLE I Fundamental condition Jiujiang rural left behind women statistics

\begin{tabular}{|c|c|c|c|c|}
\hline Age & Frequency & Percentage & $\begin{array}{c}\text { The effective } \\
\text { percentage }\end{array}$ & $\begin{array}{c}\text { The cumulative } \\
\text { percentage }\end{array}$ \\
\hline$\geqslant 56$ & 109 & 30.4 & 30.4 & 30.4 \\
\hline $46-55$ & 117 & 32.7 & 32.7 & 63.1 \\
\hline $36-45$ & 91 & 25.4 & 25.4 & 88.5 \\
\hline$\leqslant 35$ & 41 & 11.5 & 11.5 & 100.0 \\
\hline
\end{tabular}

TABLE II The women left in rural Jiujiang scale questionnaire Education

\begin{tabular}{|c|c|c|c|c|}
\hline $\begin{array}{c}\text { Cultural } \\
\text { degree }\end{array}$ & Frequency & Percentage & $\begin{array}{c}\text { The effective } \\
\text { percentage }\end{array}$ & $\begin{array}{c}\text { The cumulative } \\
\text { percentage }\end{array}$ \\
\hline $\begin{array}{c}\text { ?Junior } \\
\text { College }\end{array}$ & 11 & 3.1 & 3.1 & 3.1 \\
\hline $\begin{array}{c}\text { High } \\
\text { school }\end{array}$ & 69 & 19.3 & 19.3 & 22.3 \\
\hline $\begin{array}{c}\text { Junior } \\
\text { middle } \\
\text { school }\end{array}$ & 96 & 26.8 & 26.8 & 49.2 \\
\hline $\begin{array}{c}\leqslant \text { Primary } \\
\text { school }\end{array}$ & 182 & 50.8 & 50.8 & 100.0 \\
\hline
\end{tabular}




\section{Physical exercise status of women left in rural areas in Jiujiang}

1) Left behind women's sports concept, current situation of physical exercise, exercise frequency per week and the choice of sports etc.

The study of sports participation, mainly is to directly participate in the main, is directly involved in the physical training, experience. Survey results show that $67.1 \%$ of the women thought of labor can instead of exercise, because all parts of the body in labor also participated in the activity. Never take part in physical exercise of left behind women accounted for $73.1 \%, 11.8 \%$ of the women only occasionally participate in physical exercise, regular exercise is only $15.1 \%$. The $7.3 \%$ rear a woman participating in physical training is to improve health, $7.8 \%$ of left behind women participating in physical exercise is fun. Even if the number of weekly exercise left behind women participating in physical exercise is little, weekly frequency of physical exercise in 3 and above only $7.3 \%$, occasionally taking part in physical exercise, weekly exercise times of uncertainty, some a year but also participate in the exercise of one to two or more times, while $73.1 \%$ of left behind women never participate in physical exercise in fact, higher than the proportion, in the course of the investigation, they think others see exercise as heir participation in exercise, so the impact on the findings have. In the choice of sports, left behind women to walk. In addition the rural women to participate in physical exercise time after dinner, other times less people to participate in physical exercise.

2) Left women choose venues and sports consumption situation of physical exercise

Taking into account the rural women's cultural level is relatively low, such as the problem complexity, the questionnaire results will have a certain impact, so will they watch TV at home and in public places such as the village gossip is on the selection of activities, not really exercise field, Jiujiang women left in rural areas select the training place is the village public activities, accounting for $43.8 \%$, in fact, there are some who are in the village public chat, play cards and so. But it can be seen, rural women's activities less, entertainment content is less, not at home, is to the public places in the village, because of public places, often gathered a lot of people, there are many anecdotes spread. According to the results of the survey, the women left in rural areas of sports consumption is very low, $68.7 \%$ of the women left in rural areas the annual sports consumption is almost zero.

3) Factors of rural women are not willing to participate in physical exercise

According to the results of the survey, $65.4 \%$ of women left behind in rural is not willing to participate in physical exercise because there is no physical exercise consciousness. Because the rural women to housework and education of their children and other tasks, and tired, no time to exercise; 78.2\% of the women thought no site, $9.5 \%$ of the women thought feel shy, only $16.9 \%$ of the women thought not exercise etc..
4) The current situation of rural sports and left behind women's demand for sports activities

As China's new rural construction speed, in China, a considerable portion of the rural public sports facilities were built, but we are in the process of developing rural sports, often neglected rural sports organization, at the same time management is in a backward state. Through the investigation of rural sports organization, only $19.8 \%$ of the women thought that the village often organize sports activities, $15.6 \%$ of the women had organized sports activities is not clear, $24.6 \%$ of the women thought did not organize sports activities in the village. In addition through investigation of rural left behind women display demand survey on living district sports activities, $78.9 \%$ of the women thought countryside should increase the site equipment and facilities, $18.2 \%$ of the people think that should please guide us sports activities, $43.5 \%$ of the women left behind no demand. Thus, the women left in rural areas the demand for sports is not high, the sports concept is not strong.

\section{Factors affecting women's physical exercise of rural left behind}

\section{1) Effect of age on rural left behind women sports status}

Living in the rural women in the elderly, but taking part in physical exercise, age for women to participate in physical exercise and sports consumption significantly, the women left in rural areas in addition to the individual to participate in sports activities is to promote health, there are other women to participate in sports is just for fun, or to participate in the physical activity as a way of exchanges between neighbors; the rural women's cultural quality is generally low, and to spend money on sports consumption concepts are difficult to accept, but on whether to participate in physical exercise, times per week, exercise the choice of sports is not significantly affected, because in rural sports mainly walking, playing cards, and they have no more chance to choose, the sport is no matter in the city or in the countryside, develop sports more common.

2) Influence of labor time on the physical status of women left in rural areas

According to the results of the survey, the women left in rural areas of the working day is grown mostly in the more than 12 hours, working time is long. Influenced by traditional ideas, women outside work, but also bear the heavy housework and education of their children, work, leisure time is less, have no time to participate in physical exercise, during the process of investigation, also visited the family difficult staying women, they want to take care of the elderly and children, but also busy farm work, physical labor a long time, strength, even if have thought to exercise, no time, not physical. So, the time of rural women's participation in sports has significant effects on all aspects of labor, longer, more do not have time to participate in exercise.

\section{3) Effects of education on rural left behind women sports} status

Education is the key to influence female sports cognition. Women's awareness of sports from their childhood experiences 
in participating sports activities, this process is the sports socialization process. The woman left in the rural education is generally low, middle school and below education accounted for $77.6 \%$, only $3.1 \%$ of college and above. Education level influenced the cognitive level of individual society to a certain extent, the education level, will directly affect a person understanding of physical importance, thus affecting the physical behavior. As the investigation object degree is not high, the influence of education level on physical status of rural left behind women only significant in the "sports consumption", and on the other side effects of physical status is not significant.

4) Effect of family income on rural left behind women sports status

Economy is the foundation of social development, is also the basis for the development of mass sports, also affect the basic condition of personal participation in sports activities. The sport is the high level of demand in meeting the basic survival and security needs. For the women left in rural sports in general, they are living in luxury, they want to support their families, to pay for all the expenses, sometimes encountered bad harvest, but also for the elderly and children living expenses worry, no mood to participate in physical exercise. As for the women left in the more affluent rural areas, family income is relatively high, do not need to go out to do more of the work, time is relatively abundant, taking exercise is to spend their leisure time, and exercise the body, of course, there are also individual family wealthy women, and have the time, prefer to play cards or other entertainment and sports independent. Family income reflects a family's economic level, but also has an important impact on consumption structure of a family.

\section{Conclusions and Suggestions}

\section{A. Conclusions}

1) The current situation of sports women left in rural areas is not optimistic

The women left in rural sports concept is weak, low participation rate of sports, sports consumption is almost zero, because the rural women's cultural quality is relatively low, lack of understanding of sports, so the rural left behind to organize sports activities and facilities management requirements is not high.

\section{2) Rural sports organizations less}

Rural sports is an important part of China's sports career, but management and facilities in all aspects of the majority in the unattended state, except for daily affairs management, sports organizations and the activities of a single project rarely.

3) There are many factors influencing the rural sports current situation of women

Working time, education and household income is an important factor affecting the status of left behind women's physical exercise of rural. Culture determines its physical training on the cognitive and attitude, long working hours, high strength, individual family economic pressure, no time, no energy to participate in physical exercise; time and income plays an important role to affect a person's participation in sports.

\section{B. Suggestions}

1) Management department should strengthen the sports health education for rural women.

Through publicity and education, make the rural left behind women to change awareness of sports, establish the correct view of sports, to encourage women to participate in sports activities.

2) To increase the rural sports facilities

Government departments should strengthen the construction of sports facilities of villages in the input, based on expansion of existing venues, appropriately increase the number of sports facilities, and assign the local social sports instructors in the village to carry out technical guidance, increase the number of activities of the project, and strive to have enough activity space of rural left behind women, some guidance, project select.

3) The village committee or the women's department to coordinate the relevant departments, more care and help more difficult the women left in rural areas

Then the policy permission condition, the village committee to take proper care of relatively difficult women staying at home, can also be through incentives, to encourage the relevant policies, encourage staying women to participate in sports activities.

\section{References}

[1] Zhou Housheng. "Women left behind in rural areas of psychological research" Journal of Puyang Vocational and Technical College, pp.101104, April 2010.

[2] Xue Zishuai Zhou Huashu. "Investigation report on the situation of rural women in marriage and family" Journal of Changchun University of Technology(Social Sciences Edition), pp76-78, July 2008

[3] Ye Jinzhong. "Building New Socialist Countryside and Women's Development" Journal of central China Women's College, pp16-21, March 2009

[4] Li Ruilong, Tian Guangcheng. "Research on Health and Participation in Sports Activities of the Women Left in Henan Rural Areas" Journal of Jiyuan Vocational and Technical College, pp44-47, June 2011. 